\title{
O INGLÊS COMO LÍNGUA INTERNACIONAL E O PAPEL DO FALANTE NATIVO: UM ESTUDO EM CURSOS DE LÍNGUAS EM PORTO ALEGRE
}

\author{
ENGLISH AS AN INTERNATIONAL LANGUAGE AND THE \\ ROLE OF NATIVE SPEAKERS: A STUDY IN LANGUAGE \\ COURSES IN PORTO ALEGRE
}

\author{
Maiara Rosa Viegas ${ }^{1}$ \\ Universidade Federal do Rio Grande do Sul
}

\begin{abstract}
RESUMO
A língua inglesa é, hoje, considerada uma ferramenta do mundo globalizado, servindo para a comunicação internacional tanto para falantes nativos ou não-nativos da língua. Este trabalho objetiva analisar em que medida nove cursos de idiomas em Porto Alegre contemplam as questões do inglês como língua internacional (ILI) e qual o papel do professor falante nativo neste cenário. Para isto, diretores e coordenadores pedagógicos das escolas pesquisadas foram entrevistados através de questionários. Os resultados mostraram que os cursos estão cientes da importância do inglês como ferramenta para a comunicação internacional, mas não demonstraram estar a par das discussões e implicações intrínsecas ao conceito de ILI. Além disso, observou-se que o mito do falante nativo parece estar enfraquecido, ao menos nas escolas de maior representatividade comercial em Porto Alegre.
\end{abstract}

PALAVRAS-CHAVE: Inglês como língua internacional; falante nativo; ensino de língua inglesa.

\begin{abstract}
English is currently considered a tool for the globalized world enabling international communication, both for native and nonnative speakers of the language. This study aims at analyzing how nine language schools in Porto Alegre take into account the issues of English as an International Language (EIL) and what the role of native speakers in this environment is. For that, the school principals and pedagogical coordinators were interviewed through questionnaires. The results showed that schools are aware of the importance of English as a tool for international communication, but seem to be unaware of the discussions and implications intertwined to the concept of EIL. Moreover, the native speaker myth seems to be weakened, at least in the schools of highest commercial power in Porto Alegre.
\end{abstract}

KEYWORDS: English as an international language; native speaker; English language teaching.

\section{INTRODUÇÃO}

A Língua Inglesa tornou-se uma importante ferramenta de comunicação para o mundo globalizado, fazendo com que pessoas de diferentes países e falantes de outras línguas utilizemna como língua comum. Essa língua não é mais aprendida com o intuito de comunicar-se apenas com os falantes nativos, e sim para dar aos seus usuários meios de permearem diferentes contextos em que eles possam comunicar-se com o mundo, independente da nacionalidade ou línguas do interlocutor.

\footnotetext{
${ }^{1}$ Mestre em Linguística Aplicada pela Universidade Federal do Rio Grande do Sul. E-mail: maiararv@gmail.com.
} 
É o chamado Inglês como Língua Internacional (doravante ILI). O conceito de ILI é o de uma língua que não privilegie uma variedade em detrimento de outra, ou sejam todas as variedades são aceitas e prestigiadas, sejam elas nativas ou não-nativas. Sharifian (2009) enfatiza que ILI não apenas é uma língua para comunicação internacional, mas também para a comunicação intercultural; assim, nenhuma das variedades deve ser escolhida como a língua franca entre os povos.

Os conceitos de ILI e ILF (Inglês como Língua Franca) são similares, apesar de não seres sinônimos. Jenkins (2006) afirma que, inicialmente, ILF era visto como a língua de contato apenas entre falantes não-nativos, mas que hoje, os dois termos são usados indiscriminadamente por muitos teóricos. Friedrich \& Matsuda (2010), por sua vez, afirmam que ILF é uma função da língua inglesa em diferentes contextos, um termo mais amplo, e não uma variante. Neste trabalho, optou-se por utilizar o termo ILI por ser um termo de mais fácil entendimento para o público não acadêmico, visto que foram feitas entrevistas com sujeitos que não necessariamente frequentam a academia.

O termo ILA (Inglês como Língua Adicional) entende que a aprendizagem da língua inglesa viria como uma adição ou acréscimo ao repertório linguístico do falante, isto é, "celebraria a coexistência de várias línguas em sua insistência em não destacar uma língua em detrimento de outras, desconsiderando fronteiras políticas como demarcadoras de limites linguísticos" (JORDÃO, 2014). Sendo assim, o termo ILA entende que o inglês também pode ser utilizado para práticas locais, na própria comunidade do falante, e não apenas em comunidades estrangeiras em que o falante estaria fazendo uso da língua dos outros para se comunicar. Neste caso, estamos falando do termo ILE: inglês como língua estrangeira.

ILE coloca o falante como um estranho, um intruso que sempre terá um inglês falho quando em comparação a um falante nativo (GRADDOL, 2006). Esse pensamento parece ir ao encontro do que denominamos aqui como "o mito do falante nativo": o mito de que o falante nativo sempre será detentor de todo o conhecimento linguístico de sua língua materna e, consequentemente, o indivíduo mais bem preparado para o ensino da língua, independentemente de sua formação profissional. Embora careça de bases científicas e linguísticas, tal pressuposto, por muito tempo, alimentou o imaginário coletivo e, evidentemente, ditou certas práticas referentes a processos de ensino e aprendizagem de línguas estrangeiras, bem como à formação e contratação de professores de línguas.

Hoje, os conceitos de ILI e ILF estão presentes em discussões e currículos acadêmicos. Por outro lado, sabe-se que o ensino de inglês não é formado apenas por egressos do curso de Letras, mas também por profissionais que "estão" professores. Souza (2013) define tais profissionais como aqueles que falam fluentemente a língua a ser ensinada, mas que não são licenciados em Letras e, frequentemente, carecem de conhecimentos didático-metodológicos e enxergam na profissão professor um trabalho temporário que será abandonado quando uma oportunidade melhor surgir. No Brasil, cursos de línguas exercem uma grande influência no ensino e aprendizagem de idiomas, e, portanto, seus profissionais podem ou não estar a par das discussões do ILI e aceitação das diferentes variedades do inglês. Desta forma, a presente pesquisa buscou verificar em que medida os cursos de línguas contemplam as variedades linguísticas do inglês, e qual o papel e relevância dado aos professores falantes nativos.

A próxima seção abarcará uma breve fundamentação teórica do Inglês como língua internacional, suas variedades linguísticas e o papel do professor nativo nesse cenário. $\mathrm{Na}$ terceira seção, a metodologia e resultados da pesquisa serão apresentados. Por fim, serão feitas considerações finais acerca da pesquisa.

\section{Inglês como língua internacional e as suas variedades linguísticas}

Tornar-se uma língua internacional colocou em xeque as questões das variedades do inglês. Quem fala inglês hoje? Qual inglês está sendo falado ao redor do mundo? De forma a 
tentar mostrar o quão grande o inglês se tornou, Kachru (1985) desenvolveu um modelo de círculos concêntricos sobre a difusão do inglês. $O$ círculo interior refere-se a países onde o inglês é considerado a língua nativa, como Estados Unidos da América, países do Reino Unido, Canadá, Austrália, Irlanda e Nova Zelândia. O segundo círculo, chamado círculo estendido, refere-se a países onde o inglês é, muitas vezes, falado como segunda língua (ISL) ${ }^{2}$ e países onde o inglês também seja a língua oficial. Algumas nações pertencentes a este círculo são Índia e Cingapura. Por fim, o terceiro e último círculo é o círculo em expansão, e seus países são aqueles que não possuem uma história direta com o inglês, mas onde se podem encontrar muitos falantes da língua, como Rússia, China, Brasil, Argentina. Apesar de ser difícil definir o número exatos de falantes da língua inglesa, Crystal (2003) mostra a importância dos falantes não-nativos para que a língua inglesa seja considerada internacional: enquanto o círculo interior conteria entre 320 a 380 milhões de falantes, o círculo estendido possuiria de 300 a 500 milhões de representantes e o círculo em expansão, 500 a 1000 milhões.

Apenas esses números, entretanto, não são o suficiente para apresentar o real status da língua inglesa atualmente. Para Schmitz (2014), o modelo de círculos concêntricos de 1985 de Kachru é, hoje, incompleto: além de não apresentar e nem explicar as diferentes variedades linguísticas, não leva em consideração que os próprios círculos não são estanques ou homogêneos. Para o autor, os círculos estão ficando cada vez mais parecidos e com fronteiras difusas devido a migrações e movimentos de pessoas, e pelo fato de que muitos possuem identidades internacionais ou transnacionais [ibidem]. Entretanto, Schmitz entende que a maior contribuição de Kachru foi "trazer ao centro do palco a ideia de que o mundo é multilíngue; multilinguismo é regra, e monolinguismo é exceção"3 (SCHMITZ, 2014, p. 377). O próprio Kachru, em 2004, reformulou o seu modelo de círculos: a divisão não se daria mais pela nacionalidade do falante, e sim pelo seu nível de proficiência, ou seja, no centro do círculo estariam alocados os falantes mais proficientes, enquanto na sua periferia estariam os menos proficientes em inglês (KACHRU, 2004, apud Graddol, 2006).

É visível, assim, a influência que falantes não-nativos têm na língua inglesa, e a sua contribuição para que ela se tornasse uma língua internacional. Como consequência do alcance do inglês no mundo, surgiram questões relativas a "qual inglês" está sendo falado e utilizado. Quando tantas pessoas não nativas da língua a utilizam para a comunicação, por que haveria a necessidade de imitação das variedades nativas? Por que apagar as próprias marcas linguísticas, se elas podem representar a cultura e identidade do falante? Hoje, questões de inteligibilidade seriam mais importantes do que acurácia ao nível de falante nativo (GRADDOL, 2006). Nelson (1982 apud PICKERING, 2006, p. 221) afirma que "ser inteligível significa ser entendido por um interlocutor em certo momento e em certa situação", enquanto Smith e Nelson (1985 apud PICKERING, 2006, p. 221) afirmam que "inteligibilidade não é centrada no falante ou ouvinte, e sim na interação entre os dois". Se comunicação, conteúdo e inteligibilidade são os focos atuais, pode-se dizer que, desde que a interação falante-ouvinte aconteça, o inglês como língua internacional está servindo o seu propósito, independentemente da variedade utilizada.

Desse modo, os falantes e aprendizes de ILI não precisariam tentar imitar ou se moldar a uma ou outra variedade da língua; as suas bagagens linguísticas e culturais são marcas que não precisariam tentar ser apagadas. Sotaques e interferências da língua materna sobre a língua adicional, no contexto de inglês para a comunicação, são perfeitamente aceitáveis em um âmbito em que não comprometa a comunicação. McKay (2006 apud RAJAGOPALAN, 2009), inclusive, salienta que essas mudanças pedem que se repense a ideia de que o ensino de inglês deve nortear-se nas competências linguísticas e questões culturais de falantes nativos.

\footnotetext{
2 Inglês como Segunda Língua (ISL) seria aquele ensinado para falantes cuja língua materna não seja o inglês, mas que o estejam aprendendo em países falantes dessa língua (exclusivamente ou não).

${ }^{3}$ Do original: "it brings to center stage that the world is multilingual, multilingualism is the rule, and monolingualism is the exception". Tradução da autora.
}

Revista do GELNE, Natal/RN, Vol. 20 - Número 2: p. 3-15. 2018 
É importante salientar que o alcance global da língua inglesa fez com que não se possa mais falar em apenas duas variedades padrão. De acordo com Rajagopalan (2009), o que mais importa é a disposição dos falantes para que a comunicação aconteça, e não a uniformidade da fala. O "preço" que os falantes nativos teriam pago quando a língua inglesa se tornou internacional foi, justamente, não poderem mais dizer que a língua é propriedade sua - se um falante ou aprendiz de inglês se enxerga como um falante legítimo, a língua inglesa é sua também (NORTON, 1997, apud HIGGINS, 2003).

Entretanto, apesar das discussões teóricas sobre o tema, a ideia de que a língua inglesa é dividida em dois polos - o inglês britânico e o americano - ainda é muito forte. Não é incomum ouvir em recepções de cursos de línguas a pergunta "Vocês ensinam inglês britânico ou americano?", como se fosse preciso uma afiliação da instituição (ou do professor) a uma destas variedades. $\mathrm{Na}$ academia, apesar de as discussões do inglês como língua internacional já não serem mais novidade, ainda pode-se encontrar esta polarização no currículo de diversos cursos de Letras no Brasil: oferecem-se disciplinas de literatura americana e/ou britânica, cultura americana e/ou britânica, por exemplo. Apesar disso, pelo fato de as discussões acerca do inglês como língua internacional serem assunto de diversas aulas em nível de graduação, poder-se-ia dizer que os profissionais da área de Letras - Inglês (egressos das mesmas academias que levantam esta reflexão, apesar dos seus currículos serem muitas vezes polarizados) têm uma tendência maior para aceitar que o inglês, hoje, não pertence a uma ou duas comunidades linguísticas, e sim ao mundo.

Kramsch \& Whiteside (2008 apud RAJAGOPALAN, 2009) questionam o fato de que, apesar de as trocas globais serem cada vez mais multilíngues e multiculturais, ainda temos uma educação linguística monolíngue e monocultural, como se aquela variedade e questões culturais vistas em sala de aula fossem as únicas existentes. Partindo-se do pressuposto de que o estudante de língua inglesa não almeja aprender a língua para comunicar-se apenas com falantes nativos, mas também para equipar-se de uma ferramenta de comunicação internacional, de que maneira as questões do ILI podem entrar em sala de aula? Qual o papel da escola e do professor neste cenário?

Primeiramente, é necessário desmitificar a ideia de que muitos alunos (e muitas vezes professores) têm de que a Língua Inglesa é dividida apenas em inglês britânico e americano, como se fossem as únicas duas variedades existentes, e como se estivessem em lados opostos. Se os alunos não costumam levar em consideração outras variedades nativas, ILI será uma temática ainda mais difícil de ser abordada.

A maneira como a língua é ensinada e avaliada deve refletir sobre as necessidades e aspirações do crescente número de falantes não-nativos que utilizam o inglês para se comunicarem com outros falantes não-nativos (GRADDOL, 2006). Jenkins (2006) afirma que os professores devem abordar o inglês de forma pluricêntrica, com o intuito de conscientizar o aluno sobre a sua realidade sociolinguística e fazê-lo refletir sobre seu próprio uso da língua, em vez de aprender apenas sobre a distante maneira com que um falante nativo a utiliza. Apesar de muitas vezes o aluno que aprende uma língua adicional em sala de aula não ter oportunidades de participar do grupo em que essa língua é falada cotidianamente, o professor pode discutir diferentes contextos e interações sociais, de forma a sensibilizar o aluno para os diferentes contextos na sua própria comunidade e em outras comunidades de fala (SARMENTO, 2004).

Não se trata de ensinar todos os ingleses do mundo (até porque esta tarefa não seria possível), mas trazer o assunto para a sala de aula, sensibilizando o aluno para as questões linguísticas e sociais envolvidas na abrangência do inglês no mundo hoje. É papel do professor, então, capacitar o aluno para cautelosamente ir ao encontro das variedades, de forma que cada aprendiz possa reagir e interagir com o fato de acordo com suas próprias necessidades. Como diz Schmitt (2012), a abordagem das variedades garante que os alunos as possam tratar com respeito e, assim, compreender o cenário em que eles mesmos se encaixam. Elham \& Reza (2013) afirmam que incluir contextos e variedades internacionais em livros didáticos de Língua 
Inglesa é útil, porém, é necessário que se reflita sobre as questões e realidades do inglês como língua internacional para que se atinja um alto nível de envolvimento mental e psicológico por parte dos alunos.

Não se trata, também, de afirmar que o curso de línguas ou o professor de inglês não possam adotar um parâmetro para as suas aulas. Entretanto, esta escolha deve ser feita de forma consciente e consonante com os objetivos educacionais do aluno, e não por uma visão normativista. Nesse sentido, a noção de correção deve ser substituída por adequação em relação ao parâmetro que o aluno elege para seus objetivos educacionais: se o padrão britânico lhe propicia maior comunicabilidade no mundo do que a variedade jamaicana, por exemplo, então faz sentido que tal padrão seja tomado como parâmetro e as formas jamaicanas sejam compreendidas como variedades válidas dentre outras tantas, mas menos adequadas ao seu propósito. Isto deve ser feito criticamente, de forma que o aluno entenda e esteja de acordo com a escolha. Ainda assim, é importante salientar que essa prática não desconstrói a hegemonia ou centralidade de determinadas variedades.

Em um cenário de aceitação das variedades em esfera global, qual o papel do professor falante nativo? $\mathrm{O}$ imaginário coletivo diria que estrangeiros que tenham o inglês como a sua língua materna, possuindo ou não formação em licenciatura, seriam mais capacitados a ensinar a língua do que um profissional local da área (em países cujo inglês não seja a língua nativa). Ter um falante nativo no quadro docente poderia dar status ao curso, seria uma ação de marketing; muitos pais, por exemplo, acham bom que o filho tenha aulas com falantes nativos, pois foram educados sob essa premissa da necessidade de aquisição de proficiência igual a de um falante nativo.

O que chamamos de mito do falante nativo pode ter como origem os próprios falantes nativos. Existe uma grande quantidade de cursos de inglês especializados em ensinar estrangeiros em diversos países cuja língua materna é o inglês, e as discussões sobre ILI e ILF poderiam enfraquecer os seus negócios. Entretanto, em pesquisas internacionais, o profissional professor falante nativo pode estar perdendo créditos. Devido ao inglês ter se tornado a língua do mundo, muitos desses professores acabaram nunca aprendendo uma outra língua, pois, afinal, "os outros estavam aprendendo inglês". Com isso, falta, em muitos desses profissionais, habilidades que auxiliariam na parte didática e pedagógica, como tradução e interpretação (GRADDOL, 2006), ou o simples fato de compreender o processo de aprendizado de uma língua adicional.

No Brasil, especificamente em Porto Alegre, acreditamos que o professor nativo, com ou sem formação pedagógica, ainda seja extremamente prestigiado e valorizado, em função do mito mencionado acima. Nos cursos de Letras, os assuntos aqui discutidos parecem estar avançando, mas em que medida são postos em prática nos cursos livres? De que forma o material didático - muitas vezes estrangeiro e confeccionado por editoras internacionais com certo embasamento linguístico - tem sido devidamente aproveitado para a abertura de horizontes quanto a padrões e à configuração do inglês como língua franca? O ensino espelha as concepções linguísticas que embasam esses materiais? Tais questionamentos serão levados em consideração para observar se o mercado de ensino de inglês em Porto Alegre está em concordância com o cenário internacional vigente, conforme apresentado na seção a seguir.

\section{$2 \mathrm{O}$ inglês como língua internacional em Porto Alegre}

Tendo a supracitada discussão em vista, a presente pesquisa objetiva verificar em que medida os cursos de línguas de Porto Alegre contemplam as questões variacionais implicadas no conceito de inglês como língua internacional e qual o papel e relevância dos professores falantes nativos de inglês neste cenário. Deseja-se saber se o mercado local de ensino de inglês está em consonância com o crescente pensamento global de maior aceitação das variedades 
linguísticas, ou se o mito do professor nativo como detentor de saber e autoridade naturalmente adquiridos persiste, e, em caso afirmativo, por qual razão.

Para isto, foram entrevistados coordenadores pedagógicos, diretores e gerentes de nove cursos de língua ${ }^{4}$ em Porto Alegre. Inicialmente, planejava-se entrevistar tais profissionais dos cursos de maior representatividade comercial (número de alunos, número de filiais, renome). Entretanto, pela falta de colaboração e retorno por parte de diversos profissionais abordados, optou-se por entrevistar também profissionais de cursos pequenos e de menor representatividade no mercado porto-alegrense. No total, foram entrevistados profissionais de quatro cursos considerados maiores (que chamaremos aqui de grupo A) e cinco considerados menores (grupo B). Tal divisão foi feita com base em nosso conhecimento prévio e na observação dos contextos, por isso não julgamos necessária a coleta de dados quanto a número de alunos e de professores. Por se tratarem de informações que podem revelar a própria saúde financeira dos cursos, temíamos que esse questionamento dificultasse ainda mais nosso acesso às informações mais relevantes para a pesquisa.

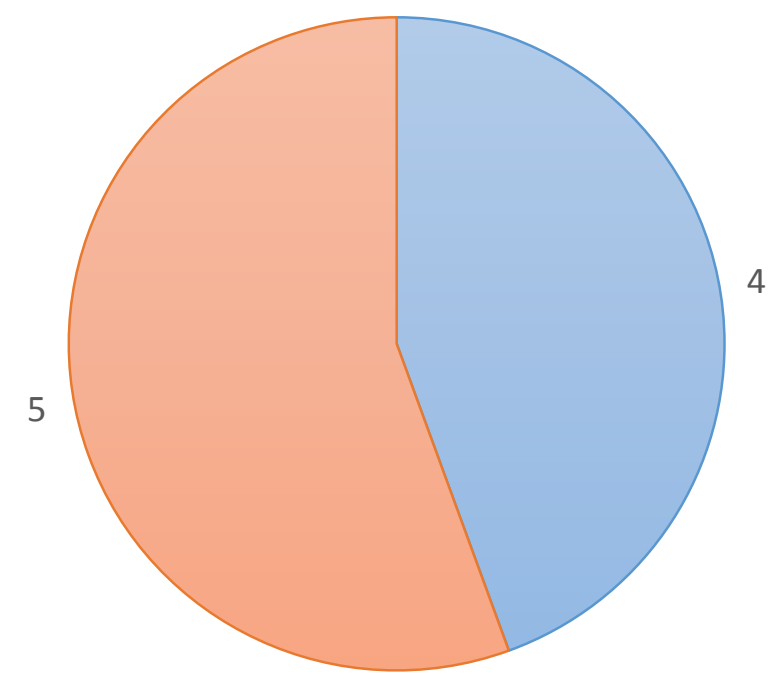

Gráfico 1: número de cursos entrevistados e sua representatividade comercial em Porto Alegre Fonte: Autora, 2018

Foi criado um questionário constituído de duas partes: a primeira tinha como objetivo obter alguns dados sobre a formação acadêmica e profissional do entrevistado (pois esperávamos que aqueles egressos de cursos de Letras/Pedagogia tivessem uma visão mais crítica sobre os assuntos aqui tratados); a segunda era constituída por perguntas relativas à visão do curso sobre o inglês como língua internacional e o papel do professor nativo na instituição. Nos sete cursos que visitamos pessoalmente, esse questionário foi utilizado como base para entrevista. Nos outros dois cursos, por não termos obtido permissão para entrevistar o profissional responsável pessoalmente, o questionário foi respondido assincronicamente e devolvido por e-mail. Além das entrevistas e questionários, foram analisados, também, os materiais didáticos ${ }^{5}$ adotados pelos cursos, a fim de se verificar em que medida estavam de

4 Por solicitação dos próprios cursos, não revelaremos os seus nomes.

${ }^{5}$ Os materiais analisados foram principalmente os do público adulto. 
acordo com as respostas dadas em relação ao inglês como língua internacional. Sabe-se que o material didático é, muitas vezes, o elemento norteador do ensino em cursos de línguas, por isso, ele deve ir ao encontro da proposta pedagógica do curso. Infelizmente, nem todas as instituições se mostraram colaborativas nesse aspecto, então foi possível analisar os materiais didáticos de sete dos nove cursos aqui representados. Os materiais didáticos analisados foram: livro didático do aluno, caderno de exercícios, manual do professor e CDs de áudio.

O presente artigo abordará os resultados de quatro das perguntas do questionário, a saber:

a) Qual é/seria a motivação do curso para a contratação de um professor nativo? Que diferencial ele traz?

b) O estrangeiro ensina os mesmos níveis de proficiência de um brasileiro, ou há alguma diferenciação? Onde o curso entende que um falante nativo seria mais bem aproveitado didática e pedagogicamente?

c) O curso contrataria um falante nativo de qualquer variedade de inglês, isto é, proveniente de qualquer país, ou existe alguma preferência de nacionalidade?

d) O material didático selecionado para níveis acima do intermediário contempla a variação do inglês internacional? Isso é um dos diferenciais levados em consideração para sua adoção?

As seções a seguir apresentarão os resultados e análises das respostas de cada uma dessas perguntas.

\subsection{Motivação e diferencial para a contratação de um professor nativo}

As respostas dos cursos do grupo A (cursos de maior representatividade comercial) para a pergunta relacionada à motivação e diferencial para a contratação de falante nativos foram:
a) demonstrar na prática o uso da língua estrangeira;
b) maior valorização do professor pelo ponto de vista do aluno;
c) habilidade de o professor trazer conhecimento de vocabulário, pronúncia e cultura.

A vantagem cultural foi trazida por mais de uma instituição, o que posteriormente fez com que nos perguntássemos: a qual cultura o curso se refere? E, principalmente, há espaço para que o professor traga aspectos culturais da sua terra natal para dentro da sala de aula e curso, ou ele fica condicionado a trabalhar aquilo que a instituição tem como padrão linguístico e cultural? E quanto ao professor brasileiro, ele é inculto por não ser nativo?

No grupo $\mathrm{B}$, as motivações para a contratação de um professor nativo se diferenciam mais. Um dos cursos, por trabalhar com um método baseado em tradução, não valoriza o falante nativo, pois o professor dessa instituição deve ter conhecimento avançado de língua portuguesa. Os outros quatro, por sua vez, dividem-se em dois subgrupos de dois grupos cada: o primeiro referente àqueles que consideram interessante ter um professor nativo em níveis mais avançados, pois os alunos se sentem motivados ao perceberem que conseguem se comunicar com um nativo, mas não consideram essencial para a política da instituição; e o segundo referente àqueles que sempre buscam ter um professor nativo trabalhando na instituição, por acreditarem em uma melhor reputação do estabelecimento de ensino pela presença do professor nativo. Ambos afirmam ser procurados por oferecerem esse diferencial.

É curioso como a valorização de falantes nativos por parte dos alunos configura um diferencial referido em mais de uma entrevista, seja do grupo A ou B. Inconscientemente, alguns cursos acabam por reforçar o mito do falante nativo, não pela parte pedagógica, mas por questões de marketing e visão do público externo das instituições. Os cursos avaliam os 
estrangeiros da mesma maneira como avaliam os brasileiros, mas imaginam que, se estrangeiros forem contratados, o aluno talvez passe a ter uma melhor percepção da instituição.

\section{$2.2 \mathrm{O}$ professor estrangeiro em sala de aula}

A próxima pergunta indaga se o estrangeiro ensina os mesmos níveis de um brasileiro ou se há alguma diferenciação, e onde o curso entende que um falante nativo seria mais bem aproveitado didática e pedagogicamente. A maioria das instituições (seis entre nove) acredita ser melhor que ele lecione níveis mais avançados ou de conversação. As três restantes afirmam que com o devido grau de formação, o professor falante nativo pode lecionar qualquer nível de proficiência, sendo que uma argumenta que, no início, por questões comunicativas, o professor não atuaria em níveis iniciais; porém, após o treinamento do método próprio da instituição, ele estaria apto a trabalhar em qualquer nível. Infelizmente, não tivemos oportunidade de verificar como esse método funciona.

As respostas a essa pergunta podem ser resumidas no gráfico abaixo:

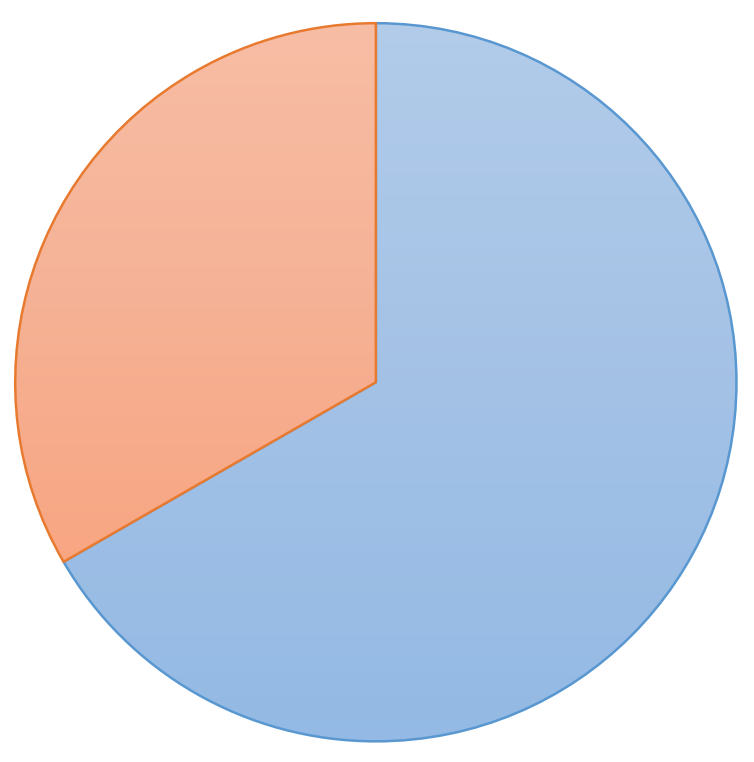

Gráfico 2: atuação do professor estrangeiro em sala de aula Fonte: Autora, 2018

\subsection{Preferências de variedade linguística do inglês}

Ao serem questionados se o curso contrataria um falante de qualquer variedade linguística do inglês, ou se existe uma preferência de nacionalidade, a maioria (seis, sendo três do grupo A e três do grupo B) respondeu não haver predileção. Um curso do grupo A prioriza a contratação de americanos; um do grupo B tem maior inclinação por nativos americanos ou ingleses; e outro do grupo B não tem preferência, desde que o sotaque e pronúncia do professor sejam de fácil entendimento e que ele não use gíria excessivamente. Tais respostas foram transpostas para o gráfico abaixo: 


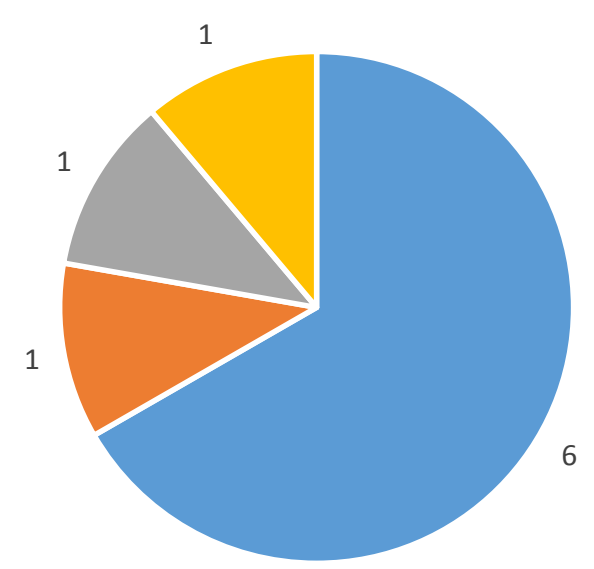

- Sem preferência

- Sem preferência, desde que a pronúncia seja de fácil entendimento

- Preferência por americanos

n $r$

Gráfico 3: preferência de variedade linguística do professor nativo Fonte: Autora, 2018

Fomos surpreendidos com essas respostas. Tínhamos como suposição que as variedades preferidas seriam o padrão britânico e americano, e a falta de favoritismo nos coloca em dúvida se os cursos realmente acolheriam um nativo de qualquer nacionalidade - incluindo, por exemplo, jamaicanos, indianos ou nigerianos -, ou se o entrevistado estava considerando apenas as variedades mais conhecidas no Brasil, como o inglês australiano, neozelandês e canadense, por exemplo. Por outro lado, parece haver uma incoerência na resposta do último curso mencionado, visto que o seu responsável afirma, em outro momento, ter foco na comunicação: se gírias e expressões idiomáticas são recorrentes na comunicação interpessoal, o professor nativo não estaria dando ao aluno mais ferramentas de construção comunicativa, ao fazer uso delas?

\subsection{O material didático e as variações do inglês}

Por fim, perguntamos se o material didático selecionado contempla as variações do inglês como língua internacional e se isso é um dos diferenciais levados em consideração para sua adoção. Dos nove cursos entrevistados, três adotam livros de editoras internacionais, e seis possuem material didático próprio, sendo que, em dois, quando o aluno chega ao nível avançado, substitui o material próprio por livros de editoras internacionais. Tentamos contatar os cursos para que pudéssemos pessoalmente analisar os materiais próprios, mas infelizmente só recebemos retorno e consentimento de quatro instituições. No total, pode-se observar os materiais didáticos de sete cursos.

Dos quatro cursos do grupo A, três responderam que o material didático contempla ILI. O primeiro afirmou que o material tem um viés britânico, mas que há diversos exercícios de listening em que a língua nativa do falante não é o inglês. O segundo possui material próprio que, nas palavras da coordenadora, segue o "padrão internacional da língua inglesa" e nos níveis mais avançados os alunos utilizam livros de editoras internacionais (inglês americano e britânico). Em 
entrevista, percebemos que a coordenadora se referia ao inglês americano ao falar de "padrão internacional do inglês". Isso nos faz indagar se o inglês americano - por ser, em geral, a variedade nativa de mais fácil contato e acesso aos brasileiros - passou a ser visto como o padrão internacional. Talvez, para muitas pessoas (sejam elas profissionais da área ou leigos em linguística), falar em inglês como língua franca é falar em inglês americano, visto que a própria cultura americana acabou por se inserir em lares de diversos países do mundo.

O terceiro curso também respondeu contemplar ILI nos materiais didáticos, visto que possuem livros de variedades britânica e americana. O quarto curso do grupo A, único a responder a pergunta negativamente, afirmou adotar o inglês americano como padrão, e em diversas unidades do material são apresentados textos cuja temática é a cultura americana, além de os alunos aprenderem músicas folclóricas do país. Esse curso também prefere a contratação de professores americanos, o que mostra existir coerência entre proposta e prática de ensino, apesar de não explorar o apelo internacional e multicultural do inglês como língua franca.

Também tivemos respostas heterogêneas dos cursos do grupo B. O primeiro afirma contemplar as diversas variações desde o primeiro nível, e utiliza a série didática Top Notch, da editora Pearson-Longman, a única, dentre as analisadas, que menciona preparar o aluno para a comunicação global. O segundo curso diz ter foco no inglês americano, trazendo algumas expressões de outros países. O terceiro não respondeu à pergunta de forma objetiva e, em nossa análise, verificamos não contemplar o ILI. O quarto curso diz ensinar "inglês internacional em todos os níveis", mas não tivemos acesso a este material; e o quinto afirma que sim, visto que utilizam os livros da Universidade de Cambridge e, por isso, estão em pleno redirecionamento para ficarem dentro dos padrões internacionais.

O gráfico abaixo representa as respostas dos nove cursos de línguas em relação ao seu material contemplar o inglês como língua internacional:

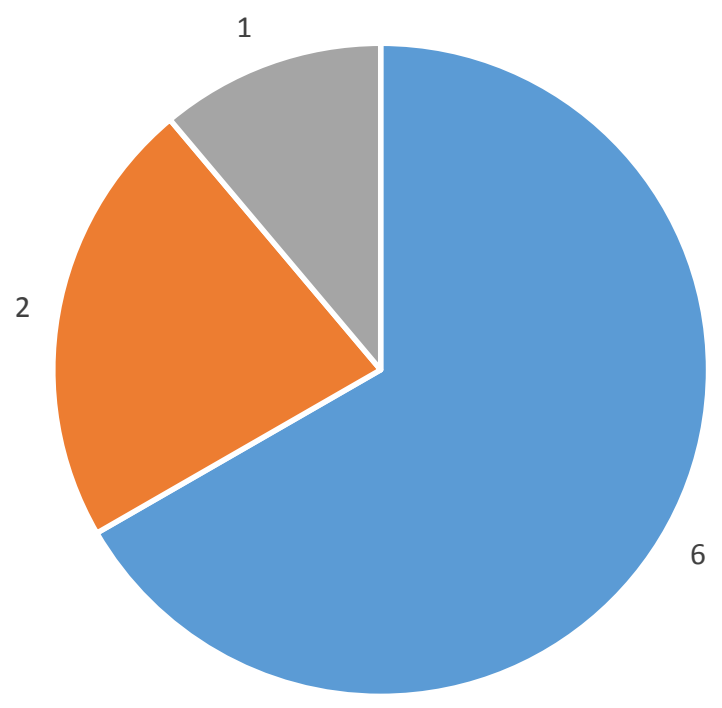

Gráfico 4: contemplação do ILI no material didático utilizado

Fonte: Autora, 2018

Contatou-se que, tanto para as editoras quanto para os entrevistados, trabalhar as diferenças variacionais da língua significa expor o aluno a diferentes sotaques e, no máximo, alguma diferença lexical ou ortográfica. Não desejamos invalidar essa abordagem, pois sabemos também ser importante na capacitação do aluno, principalmente do ponto de vista comunicativo 
(BIESWANGER, 2008), mas é visível que muitos dos profissionais entrevistados parecem não ter consciência das outras formas de variação. Por exemplo, Bieswanger (2008) afirma ser difícil diferenciar as variedades do inglês em nível gramatical, e que tal abordagem não costuma ser explorada em sala de aula, mas o que percebemos é que a maioria dos cursos aqui pesquisados não deixa de trabalhar essa questão por ser de mais difícil compreensão e visualização, e sim por não estarem cientes de que ela possa existir.

\section{CONSIDERAÇÕES FINAIS}

O presente artigo apresentou um recorte da pesquisa da autora, cujo objetivo era verificar em que medida os cursos de línguas em Porto Alegre estão de acordo com o cenário global de ensino de inglês como língua internacional, e qual o papel do professor falante nativo de inglês nesse cenário. Pelo que observamos, as instituições entendem a importância do inglês como língua internacional, e sabem que o objetivo de aprendizagem do aluno não é mais apenas comunicar-se com falantes nativos, mas parecem ainda não saber exatamente o que está por trás do conceito de ILI e como abordá-lo. A maneira encontrada até o momento é através do uso de materiais didáticos que de certa forma contemplem o inglês como língua franca através da temática, e as variedades linguísticas da língua através dos exercícios de listening

Apesar de muito ainda estar em discussão a nível acadêmico, os dados da pesquisa sugerem que tais debates e teorias ainda são principiantes em cursos de inglês. Como pudemos observar, as próprias editoras internacionais, contando com o trabalho de linguistas, ainda se pautam principalmente por questões temáticas e fonológicas (quando muito lexicais) para abordar o ILI, então podemos entender que os cursos de inglês em Porto Alegre ainda estejam começando a traçar esse caminho.

Jenkins (2006) sugere uma forma de abordar ILI e suas variedades linguísticas em sala de aula:

Para aprendizes menos proficientes, essa sensibilização poderia envolver exposição a uma gama de [world Englishes] e às variedades de ILF, enquanto para os aprendizes mais proficientes, poderia incluir discussões sobre os motivos da expansão do inglês, o desenvolvimento de diversos padrões, a relação entre língua e identidade, entre outros. Essa exposição provavelmente aumentaria a confiança dos alunos na sua própria variedade do inglês, além de reduzir o capital linguístico que muitos alunos ainda acreditam que o inglês nativo possua (JENKINS, 2006, p. 174) ${ }^{6}$.

Acreditamos ser importante a discussão do uso do inglês como língua franca/internacional com os alunos e do motivo de, na instituição de ensino, um padrão da língua ter sido eleito em detrimento de outro. Dessa maneira, acreditamos ir ao encontro do discutido por Jenkins acima, permitindo que os alunos enxerguem a língua inglesa de forma mais crítica e, principalmente, passem a entender que são tão "donos da língua" quanto um falante nativo, e por isso não precisam se colocar sempre em posição de inferioridade em comparação a ele.

Quanto ao mito do professor falante nativo, observamos que, entre os diretores e coordenadores entrevistados, ele está caindo por terra, ao menos para os cursos de maior renome no ensino de inglês. A maioria dos cursos considera que o nativo seja um diferencial, mas não mais fundamental dos pontos de vista pedagógicos e mercadológicos. Pelo que percebemos, os cursos entendem que o mito do falante nativo ainda persiste na visão do

\footnotetext{
6 Texto original: "For less proficient learners this awareness raising could involve exposure to a range of [world Englishes] and ELF varieties, while for more proficient learners, it could include discussion of the reasons for the spread of English, the development of diverse standards, the relationship between language and identity, and the like. This exposure is likely to encourage learners' confidence in their own English varieties, and in turn reduce the linguistic capital that many learners still believe native-like English to possess". Tradução da autora.
} 
público externo, razão pela qual alguns cursos de menor representatividade tenham a preocupação de contemplá-lo como estratégia de marketing.

A meu ver, um professor falante nativo da língua inglesa pode trazer um diferencial nas instituições cuja metodologia seja mais livre e os professores tenham permissão para utilizar outros recursos que não o livro didático. Inclusive, alguns cursos cujos profissionais foram entrevistados possuem metodologia e treinamento rígidos, nos quais o professor deve seguir os passos metodológicos e materiais didáticos da instituição com exatidão. Nesses cenários, o papel do professor nativo de inglês seria, sim, exatamente o mesmo do que o de um professor brasileiro (ou até mesmo estrangeiro falante nativo de outra língua que não o inglês), visto que o curso não permite ao professor nenhum tipo de flexibilidade ou criatividade.

A história do inglês como língua internacional ainda está sendo escrita, e a própria noção de padrões e variedades, nesse cenário, oferece muito a ser discutido. Esperamos que, com este trabalho, tenhamos conseguido trazer o assunto global para a realidade local, de forma a contribuir com a discussão e aumentar a conscientização dos professores, linguistas e profissionais da área de ensino de inglês como língua adicional quanto à temática da língua franca e quanto ao nosso papel como seus falantes.

\section{REFERÊNCIAS BIBLIOGRÁFICAS}

BIESWANGER, Markus. Varieties of English in current English language teaching. Stellenbosch Papers in Linguistics, v. 38, p. 27-47, 2008.

CRYSTAL, David. The Cambridge Encyclopedia of the English Language. Cambridge: Cambridge University Press, 2003.

ELHAM, Naji Meidan, e REZA, Pishghadam. Analysis of English language textbooks in the light of English as an International Language (EIL): A comparative study. International Journal of Research Studies in Language Learning, v. 2, n. 2, p. 83-96, 2013.

FRIEDRICH, P. \& MATSUDA, A. When Five Words Are Not Enough: a conceptual and terminological discussion of English as a lingua franca. International Multilingual Research Journal, v.4, n.1, p.20-30, 2010.

GRADDOL, David. English Next. British Council: 2006.

HIGGINS, Christina. "Ownership" of English in the Outer Circle: An Alternative to the NSNNS Dichotomy. TESOL Quarterly, v. 37, n. 4, p. 615-644, 2003.

JENKINS, Jennifer. Current Perspectives on Teaching World Englishes and English as a Lingua Franca. TESOL Quarterly. v. 40, n. 1, p. 157-181, 2006.

JORDÃO, Clarissa Menezes. ILA - ILF - ILE - ILG: Quem dá conta?. Revista Brasileira de Linguistica Aplicada, v. 14, n. 1, p. 13-40, 2014.

PICKERING, Lucy. Current Research on Intelligibility in English as a Lingua Franca. Annual Review of Applied Linguistics, v. 26, p. 219-233, 2006.

RAJAGOPALAN. Exposing Young Children to English as a Foreign Language: The Emerging Role of World English. Trabalhos em Linguística Aplicada, v. 48, n. 2, p. 185-196, 2009. 
SARMENTO, Simone. Ensino de cultura na aula de língua estrangeira. Revista Virtual de Estudos da Linguagem - ReVEL. Vol. 2, n. 2, março de 2004. ISSN 1678-8931 [www.revel.inf.br].

SHARIFIAN, Farzad. English as an International Language: Perspectives and Pedagogical Issues. Bristol: 2009.

SCHMITT, Tafarel. Para além do padrão? Variação linguística na coleção didática LINKS. 2012, 85 f. Trabalho de Conclusão de Curso (Graduação em Letras) - Graduação em Letras: Universidade do Vale do Rio dos Sinos, São Leopoldo, 2012.

SCHMITZ, John Robert. Looking under Kachru's (1982, 1985) Three Circles Model of World Englishes: The Hidden Reality and Current Challenges. Revista Brasileira de Linguistica Aplicada, v. 14, n. 1, p. 373-411, 2014.

SOUZA, Carlos Fabiano de. Representações do exercício docente em cursos livres de idiomas: reflexões acerca de relações dicotômicas no ensino de língua inglesa. Vértices, v.15, n. 1, p. 31-45, jan./abr. 2013

Submetido em 29/05/2018

Aceito em 12/09/2018 